Revista Chilena
De Pediatría

www.revistachilenadepediatria.cl

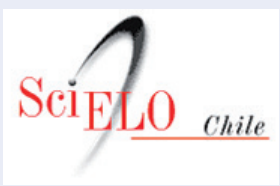

www.scielo.cl

\title{
Neurodesarrollo en los primeros 1.000 días de vida. Rol de los pediatras
}

\author{
Neurodevelopment in the initial 1,000 days. Pediatrician's role
}

Teresa Alarcón O. ${ }^{\mathrm{a}}$

aPresidenta Sociedad Chilena de Pediatría

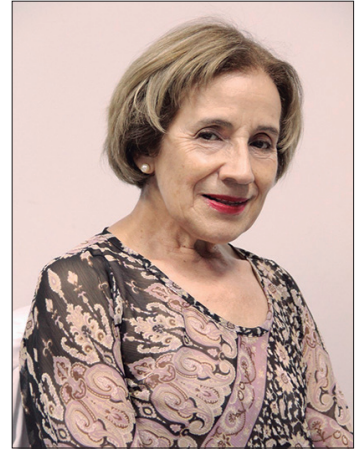

Con fecha 1 de enero de 2019 asumo la presidencia de nuestra Sociedad Chilena de Pediatría y en ese contexto es que entrego esta editorial. Agradezco al Comité Editorial de Revista Chilena de Pediatría, que ha tenido la gentileza de invitarme a entablar comunicación con sus lectores.

Aunque mi especialidad es la Gastroenterología Infantil, no por ello he olvidado mi rol de Pediatra en mi relación con los niños, su crecimiento y desarrollo y sus familias. Por ello, he elegido un tema que más bien parecería apto para un pediatra neurólogo o educadores infantiles o psicólogos. Sin embargo, lo he preferido porque es un tema transversal y porque, querámoslo o no, los pediatras somos los intermediarios entre los padres, los niños y las ciencias que nos ilustran sobre las bases de la crianza, orientada a lograr un desarrollo armonioso en lo cognitivo, lo emocional, sociabilidad, resiliencia y otras características.

El sistema nervioso humano no es muy diferente al de otras especies y es consecuencia de un complejo desarrollo evolutivo por medio del cual la especie ha adquirido las habilidades para adaptarse al medio y sobrevivir.

Todas las partes del cerebro humano son importantes e interactúan en íntima relación. En la parte posterior del lóbulo parietal se procesan las informaciones táctiles y se crean representaciones corporales tridimensionales. En el lóbulo occipital se procesan las in- formaciones visuales, incluyendo colores y movimientos. El lóbulo temporal contiene áreas responsables de procesar las señales auditivas y sociales y, también, estructuras subcorticales importantes para el aprendizaje, la memoria y las emociones. Se le conoce como sistema límbico, que incluye el hipocampo y la amígdala. El prosencéfalo es la puerta de entrada de todas las señales y regula procesos sensoriales y motores, esenciales para la planificación y el control del comportamiento. El mesencéfalo procesa percepciones y reacciones sensoriales de bajo nivel y desempeña un papel relevante en la motivación; mientras que el romboencéfalo ejerce el control de funciones básicas; como la respiración y latidos cardiacos, además de tener rol destacado en el equilibrio y el aprendizaje motriz. De los cuatro lóbulos, los frontales son los más grandes. Las áreas del lóbulo frontal están asociadas con una serie de procesos que van desde el control motor hasta "funciones ejecutivas" tan complicadas como la planificación y toma de decisiones. En la parte posterior del lóbuloparietal se sitúan el procesamiento de las informaciones táctiles y la creación de representaciones corporales tridimensionales. En el lóbulo temporal se efectúa el procesamiento de las señales auditivas y sociales. El sistema subcortical -hipocampo y amígdala- participan en el aprendizaje, la memoria y las emociones.

El movimiento corporal es controlado por la corteza motora, los ganglios basales y el cerebelo.

Correspondencia:

Teresa Alarcón 0

teritalar56@gmail.com 
La administración del lenguaje está localizada en el hemisferio izquierdo, en diestros, y es un ejemplo de lateralización evolutiva. Las áreas de Broca y de Wernicke se ocupan, respectivamente, de la producción y comprensión lingüísticas. Las áreas involucradas en la audición, así como las vinculadas a la visión se activan cuando se procesan el lenguaje y la lectura. La localización de la memoria depende del tipo de ella que se toma en consideración. Así, la "memoria de trabajo" está estrechamente relacionada con la corteza prefrontal. En cambio, aquella a largo plazo, está vinculada con el hipocampo. El cerebro está compuesto por alrededor de 100 mil millones de neuronas, con cuatro partes esenciales: dendritas, cuerpo celular, axón, terminales axónicos. Las señales eléctricas se convierten en químicas, al ser transmitidas a la neurona siguiente. Mediante estos terminales, se produce el vínculo con dendritas de otra neurona. La hendidura sináptica significa un escollo; superado mediante un neurotransmisor que, liberado, alcanza a la segunda neurona mediante receptores específicos que se ubican en sus dendritas. Histológicamente, hay variados tipos distintos de neurona, algunos de los cuales cubren grandes distancias, en tanto otros tienen axones muy cortos.

Las neuronas no son las únicas células cerebrales. Su número es superado, con creces, por varios tipos diferentes de células gliales -materia blanca- que, sirven de apoyo para su funcionamiento y cumplen funciones variadas, entre ellas asegurando aporte suficiente de oxígeno y nutrientes.

Entre los neurotransmisores se incluyen el glutamato -excitatorio- y el ácido gamma-aminobutírico (GABA), inhibitorio.

El cerebro cuenta con otros neurotransmisores: la acetilcolina se encuentra en neuronas situadas en el tronco encefálico y el prosencéfalo participando, en los procesos de atención y excitación. Este neurotransmisor se halla en las conexiones entre neuronas y músculos y es, por consiguiente, fundamental para la ejecución de los movimientos.

Dopamina se encuentra en dos áreas del mesencéfalo que son el origen de dos caminos: el nigrostriatal y el mesolímbico. El primero es esencial para el control de los movimientos y el segundo, a menudo llamado "sendero del deseo", de vital importancia para la motivación.

La noradrenalina es liberada por neuronas originadas en la profundidad del tronco del encéfalo y desempeña un papel decisivo en las reacciones de lucha o huida. La serotonina es liberada por neuronas de otra región del tronco encefálico. Se relaciona con el ciclo del sueño-vigilia, la regulación de la temperatura y la modulación del dolor y el humor.

En el cerebro destaca la corteza cerebral, un entramado de neuronas y sus prolongaciones de 3 a 4 $\mathrm{mm}$ de espesor. La presencia de pliegues complicados, hendiduras y lóbulos aumenta considerablemente su extensión, aunque la mayoría de las estructuras cerebrales es subcortical. Cuando un niño nace, la corteza muestra una plasticidad considerable y las dimensiones de algunas áreas funcionales pueden aumentar o disminuir según las vivencias o experiencias del niño; la denominada plasticidad neuronal o neuroplasticidad. Es máxima, en los primeros años del neurodesarrollo (1.000 días), cuando se adquieren los aprendizajes imprescindibles para la adaptación al medio; aunque no es infinita porque está ligada a períodos durante los que el cerebro está preparado y listo para adquirir una nueva función. La OMS definió, en 1982, el término neuroplasticidad como la capacidad de las células del sistema nervioso para regenerarse anatómica y funcionalmente, después de estar sujetas a influencias patológicas ambientales o del desarrollo, incluyendo traumatismos y enfermedades.

La neuroplasticidad ocurre y se basa en mecanismos comunes a especies tan diferentes como insectos y seres humanos. Tiene carácter adaptativo y se expresa a partir de fenómenos genéticamente programados, como el crecimiento y la migración neuronal asociada al aprendizaje $y$, en lesiones del sistema nervioso, se ha demostrado cambios favorables aún a edades mayores. El fenómeno es dependiente de reacciones biomoleculares químicas, genómicas y proteómicas que, mediante acciones intra y extra neuronales, logran generar nuevas redes neuronales. Se suele describir el sistema mesolímbico como una de las partes "primitivas" del cerebro, porque se generó en un momento temprano de la evolución. El camino dopaminérgico -o del deseo- conecta las partes del tronco encefálico que se activan cuando se experimentan estímulos motivadores con las partes de la corteza prefrontal que controlan la atención y las funciones ejecutivas. Ayuda a comportarse de una manera que maximiza las ventajas; aunque, también puede ser fuente de conductas adictivas. El camino serotoninérgico, se puede considerar el camino del bienestar: conecta partes del tronco encefálico con la corteza; por ejemplo, en las áreas prefrontales, y también con otras que tienen que ver con los niveles de memoria, estado del humor y actividades. Los trastornos de este camino están relacionados con estados de ansiedad y depresión y comportamientos obsesivo-compulsivos en conductas más complejas y planificadas como postura, desplazamiento, reconocimiento de rostros, comunicación, lenguaje verbal, interacción social, chistes, música, juego simbólico. Todos estos aprendizajes modifican las conexiones nerviosas cerebrales que, en la edad menor, tienen desarrollo rapidísimo; aunque continúan modificándose con el transcurso del tiempo. Esto implica la necesidad de calidad del entorno temprano del niño. Al nacer, 
el cerebro ya está altamente desarrollado y tiene alrededor de un cuarto del peso que alcanzará en la edad adulta. Las diferencias entre los niños se manifiestan claramente muy pronto después de nacer: algunos son irritables; mientras otros son más tranquilos. Algunos prestan más atención que otros, al igual que algunos son más sociables. Los psicólogos utilizan el término "temperamento" para referirse a estas manifestaciones, que tienen una base predominantemente biológica y cuentan con un importante componente genético. Los genes hasta ahora identificados como responsables de tal rol muestran polimorfismos con consecuencias para el temperamento de los niños. Se ha comunicado que las variaciones en la longitud de las secuencias de repetición del gen DRD4, que codifica un tipo de receptor de dopamina en el sistema mesolímbico, están relacionadas con las diferencias en el grado de apego hacia los cuidadores, y que también interactúan de manera compleja con las diferencias en el cuidado brindado por la madre. Estos factores y procesos interactúan de modo complejo, implican que cada niño es un ser único y son relevantes cuando se trata de superar adversidades y realizar plenamente sus potencialidades.

El estudio de la actividad del sistema nervioso central se efectúa actualmente con un conjunto de instrumentos vinculados a la representación óptica del cerebro: son capaces de crear mapas funcionales de la actividad cerebral basándose en cambios registrados en el metabolismo, el flujo sanguíneo o la actividad eléctrica del cerebro.

Las técnicas con que actualmente se cuenta son los potenciales relacionados con eventos (PRE o ERP: event related potentials), la imagen por resonancia magnética (IRM o MRI: magnetic resonance imaging) y la espectroscopía de infrarrojo cercano (NIRS: near infra-red spectroscopy).

La IRM estructural (IRMe o sMRI: structural MRI) permite representar ópticamente la natomía del cerebro, mientras que la IRM funcional (IRMf o fMRI: functional MRI), además,permite la medición no invasiva de la oxigenación sanguínea cerebral.

La NIRS es un método de representación óptica relativamente nuevo que saca provecho de la circunstancia de que el cráneo de los lactantes es mucho más delgado. Inmediatamente después de nacer, se produce un aumento espectacular del número de conexiones o sinapsis en todo el cerebro humano. Al cumplir el primer año de vida, el cerebro de un niño tiene casi el doble de conexiones, si se lo compara con el de un adulto. Muchas conexiones transitorias se forman en todo el cerebro del neonato, creando vínculos entre las distintas áreas cerebrales que ya no se encuentran en el adulto. La actividad de un circuito neural, determinado por la experiencia, habrá de debilitarse o se estabilizará como parte de una red permanente, factor clave para la plasticidad cerebral. Los estudios recientes han comenzado a trazar un mapa de las relaciones que existen entre el aprendizaje y aspectos del desarrollo cerebral. Las diferencias individuales en el desarrollo de la competencia lingüística se han relacionado con ciertos modelos de adelgazamiento cortical como asimismo con el desarrollo de los caminos cerebrales.

La mielina, material adiposo de color blanco compuesto de agua (40\%), lípidos (45\%) y proteínas (15\%), forma parte de la "materia blanca" del cerebro. Se acumula creando vainas alrededor de los axones. La mielinización comienza en los últimos meses de embarazo y continúa rápidamente después de nacer y a ritmo más lento, durante niñez y adolescencia. El crecimiento de la materia blanca, es más veloz durante los dos primeros años de vida, especialmente en la parte frontal del cerebro, que es la sección que participa más activamente en la memoria de trabajo, el pensamiento y la planificación.

Una dieta que suministre la cantidad suficiente de proteínas y micronutrientes, de acuerdo a OMS, durante el embarazo y a los niños después del nacimiento, es esencial para que la mielinización se lleve a cabo sin interrupción. Existen pruebas de que la carencia de vitamina B12 está relacionada con deficiencias en las funciones cognitivas.

La actividad cerebral durante estados de reposo ha sido identificada incluso en niños pequeños y los estados de reposo pueden ser muy importantes en el desarrollo infantil temprano.

Los procesos mentales ocupan redes de diferentes regiones cerebrales, cada una con especialización particular. Los estudios sobre la eficiencia de distintos tipos de redes muestran que las denominadas redes del "mundo pequeño" son las más eficaces. La organización de las redes cerebrales de los niños puede ser más flexible y plástica para reaccionar mejor a nuevos datos sensoriales o a nuevos contextos ambientales.

Los recién nacidos tienen una tendencia innata a interactuar con las personas de quienes dependen, en cuanto se refiere al cuidado (abrigo, alimentación, afecto) y al aprendizaje (idioma, normas culturales, habilidades).

Las caras y voces humanas son gratificantes para el recién nacido; como lo demuestra el hecho de que los neonatos se orientan hacia ellas y disfrutan más que con otro tipo de estímulo visual o auditivo. Si estas preferencias encuentran reacciones apropiadas, es decir, si el niño está inserto en un ambiente social estimulante y enriquecedor, entonces aprenderá rápidamente cuál es el rostro y el comportamiento de las personas. A medida que esto sucede, distintas áreas del cerebro se especializan gradualmente en reconocer los diferentes aspectos del mundo social: el movimiento y la voz humanos. La especialización de un área cerebral rela- 
cionada con el reconocimiento de las fisonomías permite el aumento gradual de la capacidad de diferenciar caras. Estudios mediante representaciones ópticas han revelado que la corteza prefrontal reacciona a este tipo de señales ya a los 5 meses de edad. El contacto visual es eficaz para atraer la atención de los niños y los ojos siguen siendo el elemento del rostro que los lactantes prefieren mirar y que generan las reacciones cerebrales más fuertes. Esto no es sorprendente, dado que los ojos son una fuente de información acerca de las intenciones o emociones de una persona.

No todos los niños desarrollan interés en interactuar con los demás y, en particular, esto se manifiesta en pacientes a quienes se ha diagnosticado diferentes niveles de trastorno del espectro autista. Estudios recientes han mostrado de qué manera los niños con trastorno por déficit de atención con hiperactividad (TDAH o ADHD: attention deficit hyperactivity disorder), tienen dificultades con la modulación de las redes neurales que participan activamente en el control de la acción. Los incentivos motivacionales, como la recompensa por una atención continua, pueden ser eficaces para mejorar el equilibrio entre redes excitadoras e inhibidoras y pueden interactuar sinérgicamente con psicoestimulantes para lograr que los niños con TDAH puedan desempeñarse al mismo nivel que aquellos sin trastorno de atención que modula lo que aprenden del ambiente. La adquisición y utilización del primer idioma es un logro complejo pero sorprendentemente rápido resultado de una intrincada variedad de procesos perceptivos y cognitivos. La sensibilidad respecto a los sonidos del habla comienza en la fase prenatal, y los recién nacidos ya muestran algunas capacidades notables en relación con el lenguaje. Estudios han revelado que los neonatos distinguen sonidos de todos los idiomas del mundo, aunque no los hayan oído nunca antes. Sin embargo, al terminar el primer año de vida, solamente conservan la habilidad de distinguir los sonidos de las conversaciones del entorno. Al llegar a la fase en que empiezan a hablar, ya poseen un conocimiento bastante complejo de las lenguas o dialectos a las que se han visto expuestos. Un elevado porcentaje de los niños de todo el mundo se encuentra expuesto desde el nacimiento a más de un idioma en su ambiente familiar. El bilingüismo temprano tiene efectos a largo plazo en las estructuras cerebrales subyacentes dedicadas al lenguaje y tal vez en otras habilidades cognitivas.

Se conoce que las experiencias, y su ubicación temporal, desempeñan papel decisivo en el desarrollo cerebral. Un ejemplo es el de los niños expuestos a privaciones psicosociales. Los niños con una historia personal en instituciones muestran un metabolismo cerebral reducido, tanto en la corteza prefrontal como en el lóbulo temporal, y también trastornos en la materia blanca en varias regiones cerebrales, junto con reducciones significativas del volumen de materia blanca y gris y aumento relativo de volumen de la amígdala.

El Proyecto de Intervención Temprana de Bucarest ha demostrado menor actividad cerebral en la corteza de niños institucionalizados en comparación con otros no institucionalizados. A los 42 meses de edad, los previamente institucionalizados que habían sido colocados en familias adoptivas antes de cumplir 2 años registraban, en sus EEG, una actividad que se parecía más a la de niños sanos.

Los niños sometidos a malos tratos -abusos de naturaleza sexual, física o emocional, abandono- tienen mayor probabilidad de desarrollar problemas psicológicos. Investigaciones en ese sentido han mostrado el impacto de las experiencias adversas en cuanto al cuidado recibido, pueden afectar las estructuras y funciones cerebrales, y su influencia en el desarrollo psicológico y emocional. A la fecha se cuenta con evidencia de que las adversidades en la infancia están vinculadas con un desarrollo atípico del eje hipotalámico-hipofisarioadrenal (HHA o HPA: hypothalamic-pituitary adrenal axis) que controla la emisión de hormonas del estrés, con pautas de capacidad de respuesta reducida o exagerada, según los informes.

Los niños en su gran mayoría aprenden a reconocer su entorno, a caminar y relacionarse socialmente de forma espontánea. No precisan para ello de un aprendizaje dirigido y activo. Al madurar las estructuras cerebrales necesarias para asumir nuevas funciones, simplemente serán incorporadas. El aprendizaje es una cualidad humana presente durante toda la vida, aunque disminuye con la edad. Hay habilidades que requieren de enseñanza dirigida, esfuerzo y demostrarán mejorías con la práctica y la experiencia. Si los niños son saludables y en condiciones de aprendizaje, si pierden la oportunidad, les será más difícil aprender. A estas circunstancias y períodos se les ha reconocido como períodos críticos.

En el desarrollo de los niños, especialmente desde su primera edad, es deseable la educación armoniosa y equilibrada; tanto en su desarrollo intelectual como emocional, buscando una evolución equilibrada del sistema nervioso cerebral a la vez que integrarlos y resguardar el legado humano evolutivo que incluye los sistemas instintivo, emocional, reflexivo o de los lóbulos prefrontales. Entre las principales funciones de los lóbulos prefrontales están funciones cognitivas que son atención sostenida y selectiva, lenguaje, memoria, creatividad, razonamiento lógico y funciones ejecutivas que implican básicamente: planificación a largo plazo, perseverancia, prever problemas, resolución de conflictos, retardo de la gratificación, vetar impulsos emocionales, ser empático, desarrollar conductas éticas y altruismo. Los lóbulos prefrontales se 
activarán a los 500 milisegundos (camino largo); por lo que, al inicio, sólo podrán ser mudos espectadores de acontecimientos instintivos, aunque les queda como última opción, si están preparados, poder vetar la conducta iniciada por las áreas primitivas. Por esta razón, todos los comportamientos humanos, por lo menos en los primeros milisegundos, son siempre inconscientes.

Entre las regiones cerebrales de más lento desarrollo está el córtex prefrontal. En efecto, esta región continúa desarrollándose hasta principios de la tercera década de la vida. La investigación sobre imágenes cerebrales y estudios realizados en pacientes afectados por lesiones cerebrales sugieren que el córtex prefrontal es vital para controlar la atención, el pensamiento y el comportamiento, en parte porque establece el puente entre los centros de control perceptual, emocional y motor, situados en otras partes en el cerebro. La lentitud del desarrollo del córtex prefrontal y su importancia para el control ejecutivo han llevado a reconocer que básicamente sería normal que ciertos desafíos básicos de la vida diaria, tales como no jugar con juguete prohibido, sean difíciles, incluso para niños con desarrollo normal. De hecho, la comprensión y el manejo de las emociones morales requieren la internalización de normas y principios morales compartidos por la comunidad. El ser humano también debe estar en capacidad de percibir y comprender las emociones de otras personas (empatía), lo que implica comprender sus creencias y sus actitudes. De esta manera, el desarrollo emocional y el social están estrechamente ligados.

Las neuronas conocidas como "en espejo" se encuentran en primates, humanos y algunas aves. En el humano se las encuentra en el área de Broca y la corteza parietal. Las neurociencias les otorgan un papel muy relevante e importante entre las capacidades cognitivas relacionadas con las funciones sociales; como empatía (capacidad de ponerse en el lugar de otro) e imitación. La ciencia emergente que estudia el desarrollo cerebral indica que, para un desarrollo adecuado, el cerebro del niño necesita cultivarse mucho antes de los 6 o 7 años, cuando comienza la escolarización formal.

Sin las amenazas de eventuales riesgos biológicos y psicosociales y con un ambiente de cuidado que apoye el desarrollo cognitivo y socio-emocional, de los niños experimentan un desarrollo cerebral sano que permite alcanzar el máximo de sus potencialidades. El desarrollo afectivo adaptativo está ligado a su bienestar; mientras las dificultades de regulación emocional están ligadas a perturbaciones del humor y a problemas de comportamiento. El desarrollo emocional se produce gracias a una variedad de destrezas cognitivas, entre las cuales se encuentra aquella adecuada para regular voluntariamente su comportamiento con flexibilidad. La regulación cognitiva y la regulación emocional pare- cen desarrollarse en conjunto. Este desarrollo, intenso durante el periodo preescolar continúa, más calmadamente, toda la infancia y adolescencia.

Actitudes parentales como calidez, sensibilidad y disciplina suave, ligadas a un vínculo padres-hijo seguro y recíproco, están asociadas a mejores destrezas de funciones ejecutivas en los niños. Igualmente, se ha mostrado que los programas educativos preescolares centrados en la enseñanza de las habilidades de autorregulación mejoran significativamente el desarrollo del control ejecutivo. La plasticidad del sistema que sustenta la regulación cognitiva y emocional podría estar ligada a la maduración gradual de este sistema, que se prolonga a todo lo largo de las primeras dos décadas de la vida. Las intervenciones dirigidas a disminuir riesgos y fomentar el desarrollo infantil temprano, en los primeros mil días de vida, brindarán rendimiento a lo largo de la vida contribuyendo a la realización y sostenibilidad de mejoras en el desarrollo de la generación siguiente. Estos conocimientos son sumamente importantes para que las personas puedan alcanzar la capacidad de auto motivarse y perseverar en sus sueños pese a las adversidades y las frustraciones que se le pueden cruzar en el camino.

Sin embargo, no hay que olvidar que cualquier niño de corta edad tendrá dificultad para planificar por adelantado, resistir tentaciones, regular emociones y permanecer concentrado en una tarea. Los límites en el funcionamiento ejecutivo pueden mostrarlo como caprichoso y travieso, como cuando insisten en salir a jugar al frío, la lluvia o comer una golosina pese, a advertencias que no la podrán comer sino hasta después del almuerzo. Las funciones ejecutivas son predictivas de repercusiones futuras en la vida. Las diferencias individuales en funciones ejecutivas al inicio del jardín infantil predicen logros académicos futuros, y pueden ser más críticas para el éxito temprano que la familiaridad con números y letras. Los comportamientos auto-regulatorios predicen habilidades sociales, como relaciones con padres, profesores y pares, compromiso escolar, salud, riqueza y frente a carencias en estos aspectos, a criminalidad en la vida.

El enfoque pedagógico basado en el uso del juego fomenta el desarrollo y aprendizaje en diversas áreas. El juego libre y el guiado son dos tipos distintos de aprendizaje: el primero está dirigido por el niño y su motivación es interna y, el segundo, es guiado por el adulto y se orienta a un objetivo específico de aprendizaje. Aunque el juego es un derecho legítimo en la infancia temprana, así como uno de los caminos más naturales en exploración y aprendizaje, los niños pequeños disponen cada vez de menos oportunidades de juego, tanto en el hogar como en la escuela. La importancia de la preparación para la escuela ha hecho que los programas de infancia temprana prioricen actividades y 
pruebas estructuradas; en detrimento del aprendizaje físicamente activo basado en el juego. Este enfoque de aprendizaje tradicional tiende a reducir la motivación del niño para aprender y tiene efecto negativo sobre su atención y regulación del comportamiento.

Afortunadamente, en Chile, y especialmente en Santiago, existen escuelas que siguen los principios de Montessori y Waldorf; aunque, por ser colegios privados, su influencia no es masiva.

El juego libre parece ser especialmente beneficioso para el desarrollo de las competencias sociales y la autorregulación. Por ejemplo, el juego dramático, una forma de juego libre, permite a los niños resolver problemas al enfrentar conflictos, inhibir sus comportamientos impulsivos, expresar emociones, seguir normas sociales y apoyar el bienestar emocional de los demás.

En comparación con el juego libre, el guiado parece más efectivo en la adquisición de habilidades académicas. Al estructurar el entorno, incorporar objetivos de aprendizaje y modificar juegos prediseñados, padres y maestros parvularios pueden mejorar las oportunidades de aprendizaje de niños pequeños. La falta de una formación formal y la presión creciente para alcanzar los objetivos de aprendizaje prescritos pueden ser factores que contribuyen a estas dificultades. En com- paración con los niños de nivel socioeconómico más alto, los de comunidades con ingresos bajos tienden a participar más en actividades de ocio (como medios digitales) que a participar en actividades en exteriores o lúdicas. Dado el número cada vez mayor de niños usuarios activos de dispositivos electrónicos, se recomienda a los padres controlar la cantidad de tiempo que los niños pasan con los dispositivos y los tipos de juego que juegan con ellos. Al proveer una gama de juguetes diversa (ejemplo: bloques de madera, materiales de manualidades, rompecabezas, libros, disfraces) se estimula a los niños a crear juegos dramáticos y explorar nuevas posibilidades

No existe un consenso en la investigación ni en las políticas sobre los medios de aprendizaje ideales para los niños.

Si realmente nos concentramos en lo que los niños necesitan para tener éxito en el mundo de mañana, no podemos simplemente centrarnos en una estrategia en detrimento de otra; la investigación debe determinar un equilibrio productivo y apropiado para el desarrollo.

\section{Conflicto de intereses}

La autora declara no tener conflicto de intereses. 